\title{
Self-Healing of Cracked Textile Reinforced Concrete Layers ${ }^{+}$
}

\author{
Martin Lenting ${ }^{1,2, *}$ and Jeanette Orlowsky ${ }^{2, *}$ \\ 1 Department of Building Physics, Faculty of Civil Engineering, Münster University of Applied Science, \\ 48149 Münster, Germany \\ 2 Department of Building Materials, Faculty of Architecture and Civil Engineering, Technische Universität \\ Dortmund, 44227 Dortmund, Germany \\ * Correspondence: martin.lenting@fh-muenster.de (M.L.); jeanette.orlowsky@tu-dortmund.de (J.O.) \\ + Presented at the 1st International Conference on Smart Materials for Sustainable Construction-SMASCO \\ 2019, Luleå, Sweden, 10-12 December 2019.
}

Published: 18 November 2019

\begin{abstract}
Sustainable maintenance of existing steel-reinforced concrete structures becomes more important. Using non-reinforced sprayed mortar to maintain these structures often leads to cracks in this repair layer due to the alteration of crack widths in the ordinary structure. The water impermeability as well as the durability of the sprayed mortar will be reduced due to the described cracks. This presentation shows a solution for the described problem. The use of carbon yarns with a special inorganic coating as reinforcement in sprayed mortars leads to a self-healing of the arising cracks. Due to the inorganic coating applied on carbon yarns the excellent bond between mortar and yarn results in a fine distributed crack image with crack width below $0.1 \mathrm{~mm}$. It is shown that these cracks heal themselves. Consequently we can provide a mainly mineral protection layer for existing steel reinforced concrete structures which is impermeably to water based solutions. The presentation focuses on the material development and characterization.
\end{abstract}

Keywords: self-healing; textile reinforced concrete 